\title{
The Selection and Application of Anticorrosive Materials for Flue Gas Desulfurization (FGD) System in Cement Plant
}

\author{
Yuyun Liao \\ Hefei Cement Research \& Design Institute Corporation Ltd., Hefei, China \\ Email: 153062424@qq.com
}

How to cite this paper: Liao, Y.Y. (2020) The Selection and Application of Anticorrosive Materials for Flue Gas Desulfurization (FGD) System in Cement Plant. Journal of Materials Science and Chemical Engineering, 8, 79-90.

https://doi.org/10.4236/msce.2020.84006

Received: February 14, 2020

Accepted: April 24, 2020

Published: April 27, 2020

\begin{abstract}
This paper combined with the actual case of flue gas desulfurization (FGD) system in cement Plant, analyzes the corrosion environment in each area of the FGD system, and selects appropriate anticorrosive materials for different corrosion environment, so as to provide operating experience and reference for the safe, stable and efficient operation of the FGD system.
\end{abstract}

\section{Keywords}

Cement Plant, Flue Gas Desulfurization System, Corrosion Environment, Selection of Anticorrosive Materials

\section{Introduction}

At present, with the national restrictions on mining and the reduction of high-quality limestone stock, many cement plants have to use low-grade limestone, with sulfur content ranging from $0.2 \%$ to $2.0 \%$, resulting in excessive $\mathrm{SO}_{2}$ emission concentration in the flue gas from the kiln tail, and some enterprises even reach a high emission concentration of about $3000 \mathrm{mg} / \mathrm{Nm}^{3}$. In order to solve the problem of excessive $\mathrm{SO}_{2}$, many cement plants adopt limestone gypsum desulfurization technology to solve it. In the wet FGD process of cement plant, due to the variety of raw materials/fuels and complex components of cement kiln, especially some production lines for collaborative disposal of domestic garbage and sludge, the composition of flue gas is more complex, including corrosive substances such as $\mathrm{SO}_{2}, \mathrm{HF}, \mathrm{HCl}, \mathrm{NOx}$ and heavy metals. During the operation of wet FGD system, the corrosion environment of wet FGD device is more complex. Therefore, the correct selection and application of anti-corrosion 
materials will directly affect the service life of the wet desulfurization system of cement kiln and the requirements of environmental protection. Therefore, based on the actual cases, this paper analyzes the corrosion environment of the wet desulfurization system of cement kiln, and puts forward the corrosion prevention measures and material selection in different corrosion environment and regions, so as to ensure the safe, reliable, efficient and economic operation of the desulfurization device of cement kiln, as well as the sustainable development of energy conservation, consumption reduction and environmental protection.

\section{Process Flow of Flue Gas Desulfurization System in Cement Plant}

Figure 1 shows the process flow chart of a cement kiln FGD system:

As shown in Figure 1, the cement kiln wet desulfurization process uses the kiln ash collected by the bag filter at the end of the cement kiln as the desulfurization absorbent. The kiln ash is taken into the desulfurizer bin for storage, then it is metered into the slurry preparation tank, mixed with water and stirred into the slurry, then it is pumped into the absorption tower by the slurry pump,

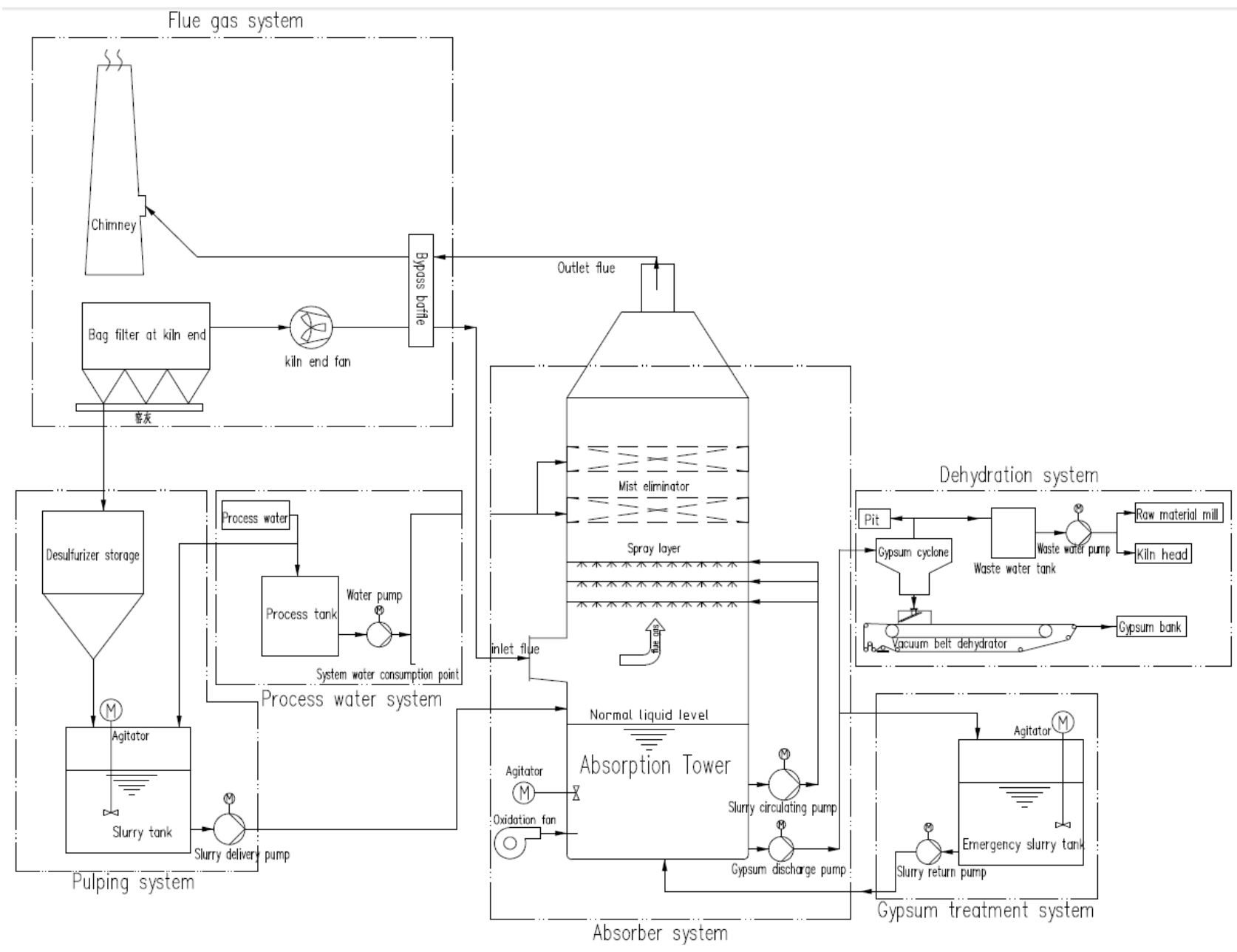

Figure 1. The process flow chart of a cement kiln FGD system. 
atomized by the spray system, and the kiln slurry liquid is in full contact with the original flue gas at the end of the kiln. The $\mathrm{SO}_{2}$ in the original flue gas is in contact with the slurry. The calcium oxide in the liquid and the oxidized air blown in are removed by chemical reaction, and the gypsum finally generated is recycled after dehydration in the dehydration unit. The purified flue gas is removed from the entrained small liquid drop by the demister and discharged into the atmosphere through the chimney. The desulfurizing slurry can be recycled and the utilization rate of desulfurizing agent is very high. The typical cement kiln ash gypsum wet flue gas desulfurization equipment mainly consists of flue gas system, absorption tower system, preparation system, gypsum dehydration system, accident treatment system, waste water treatment system, etc.

\section{The Corrosion Environment analysis of Flue Gas Desulfurization System in Cement Plant}

In the wet desulfurization system of cement kiln, because the raw flue gas contains dust, $\mathrm{SO}_{2}, \mathrm{HF}, \mathrm{HCl}, \mathrm{NOx}$, water vapor and other components, complex components such as $\mathrm{H}_{2} \mathrm{SO}_{3}$ and $\mathrm{H}_{2} \mathrm{SO}_{4}$ will be generated when the temperature is low. The desulfurization equipment bears a variety of physical, chemical, temperature and mechanical loads, including liquid components $\mathrm{SO}_{3}^{2-}, \mathrm{SO}_{4}^{2-}, \mathrm{F}^{-}, \mathrm{Cl}^{-}$ is the main cause of equipment material corrosion [1]. Due to the complex operation environment of the desulfurization system, it is necessary to analyze the corrosion environment in specific areas so as to reasonably select anti-corrosion materials for the desulfurization unit.

\subsection{Corrosion Environment Analysis of Desulfurization Absorption Tower}

Absorption tower is the core component of the whole FGD system. In the operation of the system, the absorption tower is in the harsh environment of high temperature, high humidity and high wear, and its corrosion environment is very bad.

\subsubsection{Corrosive Environment in Inlet Flue Area}

For the cement kiln, the flue area at the inlet is dry area, and the temperature of the original flue gas is generally about $150^{\circ} \mathrm{C}$, which is significantly higher than the dew point of sulfuric acid, without water mist, in a dry and hot state, basically without corrosiveness. The dry/wet interface is about 2 meters before the inlet of the absorption tower, and the original flue gas begins to contact with the slurry. Due to evaporation, the concentration of dissolved salt in the sediment filtrate in this area is very high, containing high concentration of $\mathrm{Cl}^{-}$ and $\mathrm{SO}_{4}^{2-}$, and the flue surface is easy to deposit solid particles and scale. The results show that the mass concentration of $\mathrm{Cl}^{-}, \mathrm{F}^{-}, \mathrm{SO}_{4}^{2-}$ in the sediment solution at the inlet of the absorption tower can even reach $100,000 \mathrm{mg} / \mathrm{L}, 10,000$ $\mathrm{mg} / \mathrm{L}$ and $50,000 \mathrm{mg} / \mathrm{L}$, and the $\mathrm{pH}$ value is about 3 [2], The corrosion environment is very severe. 


\subsubsection{Corrosion Environment in Slurry Area}

The slurry area is used to store recycled slurry, so as to ensure the retention time of slurry in the absorption tower and make $\mathrm{CaSO}_{3}$ fully oxidized to $\mathrm{CaSO}_{4}$. There are almost all corrosion factors in FGD system: acid corrosion, chlorine corrosion, erosion corrosion of high-speed fluid and its particles. In general, the concentration of chloride ion in the domestic control absorption tower is lower than $20,000 \mathrm{ppm}$, and the solid content of slurry is $10 \%-20 \%$. Therefore, gypsum grains, limestone and other media particles will cause serious wear on the wall and components of slurry area [3]. $\mathrm{Cl}^{-}$in slurry will cause pitting corrosion of metal materials, and low $\mathrm{pH}$ value will aggravate the development of pitting corrosion. Due to the high-speed fluid and particles in the slurry, the bottom plate and side wall of the absorption tower will suffer slurry abrasion. If the fixed pipe network type oxidation gas distribution device is adopted, when the nozzle is close to the bottom of the tower, the air flow will also wash the bottom plate. Due to the synergistic effect of electrochemical corrosion and erosion wear, the metal flow passage parts of the absorption tower and the agitator blades accelerate the abrasion of the pump, especially when the content of circulating slurry solids and $\mathrm{Cl}^{-}$is high, the service life of the worn parts will be greatly shortened. Therefore, the corrosion-resistant and wear-resistant materials must be selected as the corrosion-resistant materials.

\subsubsection{Corrosion Environment in Spray Area and Demister Area}

In the slurry spray area of the absorption tower, the raw flue gas is in full contact with the slurry, and the temperature of the flue gas is reduced from $80^{\circ} \mathrm{C}-90^{\circ} \mathrm{C}$ to $45^{\circ} \mathrm{C}-50^{\circ} \mathrm{C}$. The calcium carbonate in the slurry can provide enough alkalinity to neutralize the acid in the flue gas, and the $\mathrm{pH}$ value is moderate. When the spray slurry directly washes the wall and components of the absorption tower, it will produce abrasion, but the degree of abrasion is less than that of the slurry area. At the same time, due to the rapid change of temperature, the thermal expansion state of the anticorrosive lining in this area will be different, forming uneven thermal stress, leading to lining cracking and peeling. The existence of thermal stress increases the microcracks and interface pores of the non-metallic lining, and the medium will penetrate into the lining from these defects, which will lead to the failure of anti-corrosion materials. At the same time, in the desulfurization system, the solid particles in the slurry are composed of dust, limestone and calcium sulfate. When the limestone slurry is ejected from the spray pipe by the slurry circulating pump under pressure, it will wash the wall surface of the absorption tower and the lining of the components, resulting in serious abrasion of the anti-corrosion lining.

\subsubsection{Corrosion Environment of Flue Gas Outlet Area and Public Flue Gas}

The flue gas outlet area extends from the absorber demister outlet to the system outlet damper. For FGD system without reheater, the flue gas temperature in this area is generally about $50^{\circ} \mathrm{C}$, and water film will be formed on the flue gas 
wall with acid dew point lower than the flue gas, and they will continue to absorb $\mathrm{SO}_{2}$ or $\mathrm{SO}_{3}$ in the flue gas, which makes the residual alkali in the water film quickly consumed, and gradually forms acid solution with lower $\mathrm{pH}$ value, so the $\mathrm{pH}$ value of the condensate at this area is generally much lower than that at the upstream side of the demister, About less than 3.5, the measured $\mathrm{pH}$ value of condensate is 2.1 [4], so as to erode the surface of the anticorrosive coating.

Public outlet flue refers to flue gas between flue gas outlet damper, bypass damper and chimney inlet. When the unit starts, stops and FGD fails to stop, the corrosive environment in this area needs to pass through the high temperature $\left(120^{\circ} \mathrm{C}-160^{\circ} \mathrm{C}\right)$ raw flue gas for a long time. When there is no flue gas heater, the corrosion environment in this area is similar to that in the flue gas outlet area. If the public outlet flue is too long, good insulation measures shall be taken for the flue gas.

\subsection{Corrosion Environment of Chimney}

Under normal conditions, the flue gas temperature of the chimney of the cement kiln is above $100^{\circ} \mathrm{C}-110^{\circ} \mathrm{C}$, the exhaust gas is dry, the inner wall of the chimney is dry, and the gas only causes gas corrosion to the materials of the inner wall of the chimney, with slight corrosion.

After adding a wet desulfurization device, since there is no flue gas heating device, the flue gas discharged through the chimney is in the state of "wet flue gas $\left(\sim 50^{\circ} \mathrm{C}\right)$ " of low temperature, saturated and dilute acid type. The flue gas temperature in the chimney is lower than the acid dew point, and the flue gas condenses and condenses into acid liquid. The generated dilute acid liquid drops are mainly sulfuric acid and sulphurous acid, as well as micro amounts of hydrofluoric acid, hydrochloric acid and nitric acid. The $\mathrm{pH}$ value of the mixed acid is $1.0-2.0$, which is very corrosive and permeable. The inner wall of the wet chimney is exposed to this kind of strong mixed acid environment for a long time, which increases the risk of chimney leakage and corrosion, and reduces the safety and reliability of the structure. Research shows that at $40^{\circ} \mathrm{C}-80^{\circ} \mathrm{C}$, low concentration of acid has stronger corrosiveness to structural materials. For example, at $40^{\circ} \mathrm{C}-80^{\circ} \mathrm{C}$, the corrosion rate of dilute acid to steel is $3-8$ times of that at other temperatures. Therefore, the corrosion degree of this low temperature, high humidity dilute acid corrosion condition is more serious than that of dry chimney without desulfurization [5].

At the same time, when the chimney is in normal operation, the inner wall is almost in the state of full positive pressure. Although the positive pressure of the chimney is not large, the acid liquid will form a certain seepage pressure on the chimney surface under the influence of the positive pressure operation of the flue gas [6], However, it has a great influence on the corrosion of the chimney, which can make the smoke and acid liquid pass through the lining brick or concrete layer, so the wet smoke which causes the corrosion to the inner wall of the chimney is usually regarded as "high" chemical corrosion grade. Therefore, the 
safety design of chimney structure should be based on the level of strong corrosive flue gas.

\subsection{Corrosion Environment of Slurry Pipeline, etc.}

The slurry pipeline mainly transports limestone slurry. The physical and chemical characteristics of slurry (such as density, chloride content and size of slurry particles) will affect the selection of pipeline materials and types. Because the limestone slurry usually contains about $20 \%-23 \%$ (mass ratio), which contains a large number of solid particles, these solid particles have strong abrasiveness. Generally, the $\mathrm{pH}$ value of the slurry at the bottom of the tower is $5-6$, and $\mathrm{Cl}^{-}$ can be enriched more than $80,000 \mathrm{mg} / \mathrm{L}$, which will produce strong corrosiveness under the condition of low $\mathrm{pH}$ value.

\section{Selection of Anticorrosive Materials}

\subsection{Selection of Anticorrosive Materials for Absorption Tower}

\subsubsection{Selection of Anticorrosive Materials for Inlet Flue of Absorption Tower}

Considering the corrosion environment of the flue in front of the inlet of the absorption tower, during the selection of anti-corrosion materials, the flue from the dust remover to 2 meters in front of the absorption tower can be directly made of carbon steel due to the high temperature and low corrosion of the flue gas, and only the high-temperature anti-corrosion paint can be applied inside the flue.

For the flue at $2 \mathrm{~m}$ in front of the absorption tower, corrosion-resistant alloy materials can be used for corrosion protection. The 2-meter flue in front of the absorption tower entrance of a $2500 \mathrm{t} / \mathrm{d}$ cement production line of Hefei Institute is designed as 2205 alloy + carbon steel lining composite structure, see Figure 2 for details. 2205 alloy is generally $2-3 \mathrm{~mm}$ thick and $2 \mathrm{~m}$ wide. Due to the excellent corrosion resistance of 2205 alloy, there is no corrosion in operation at present.
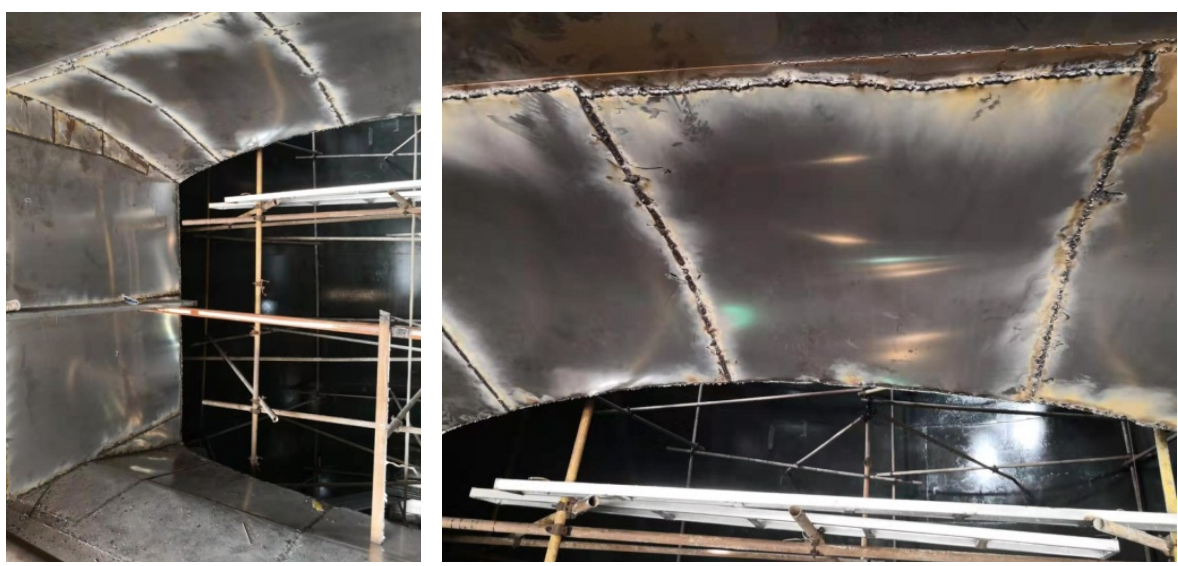

Figure 2. 2205 alloy + carbon steel lining and anti-corrosion drawing in the flue $2 \mathrm{~m}$ in front of the absorption tower. 


\subsubsection{Selection of Anticorrosive Materials for Absorption Tower}

According to the corrosion environment in different areas of the absorption tower, different anticorrosive materials are used. The selection of anticorrosive materials in the main area of absorption tower of a wet desulfurization project of Hefei Institute is shown in Figure 3 and Table 1.

It can be seen that in addition to the inlet flue part, the glass flake resin is basically used for anticorrosion. Considering the different corrosion environment in each area, the thickness of anticorrosion layer is changing. Below are some site construction photos.

As shown in Figure 4, the bottom plate and side plate of the absorption tower are coated with glass flakes. Figure $\mathbf{5}$ shows the spray layer coated with glass scales.

\subsection{Requirements and Selection of Anticorrosive Materials for Chimney}

In table 11.2.1 of the national standard code for design of chimneys (GB50051), "requirements for selection of anticorrosive materials for steel inner barrel of sleeve or multi tube chimneys" are specified in Table 2 below.

In the power industry standard "technical code for design of civil structure of thermal power plant" DL 5022, clause 8.4.1, Clause 1 states that "when the strong corrosive flue gas is discharged, the sleeve type or multi pipe type chimney shall be used generally".

In the first paragraph of article 8.4.5, it is specified that "when the strong corrosive flue gas is discharged, GGH is not set, and two furnaces share one exhaust

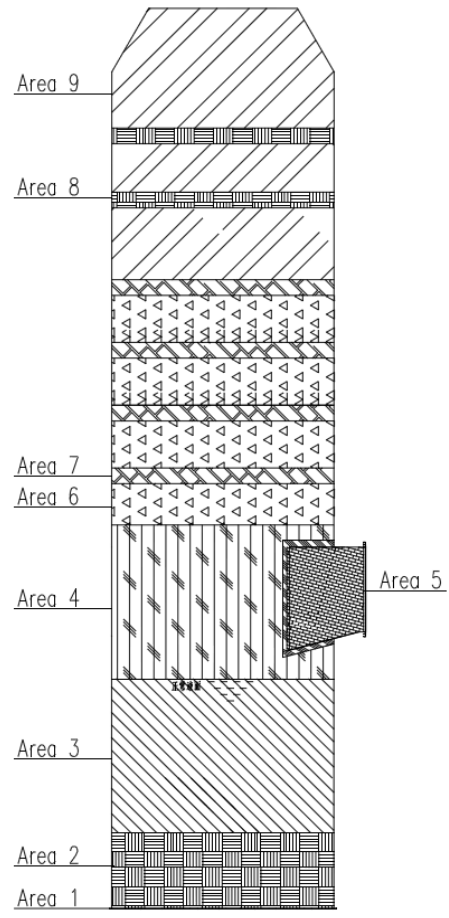

Figure 3. Anticorrosion area division of desulfurization absorption tower. 
Table 1. Anti corrosion in different areas of desulfurization absorption tower.

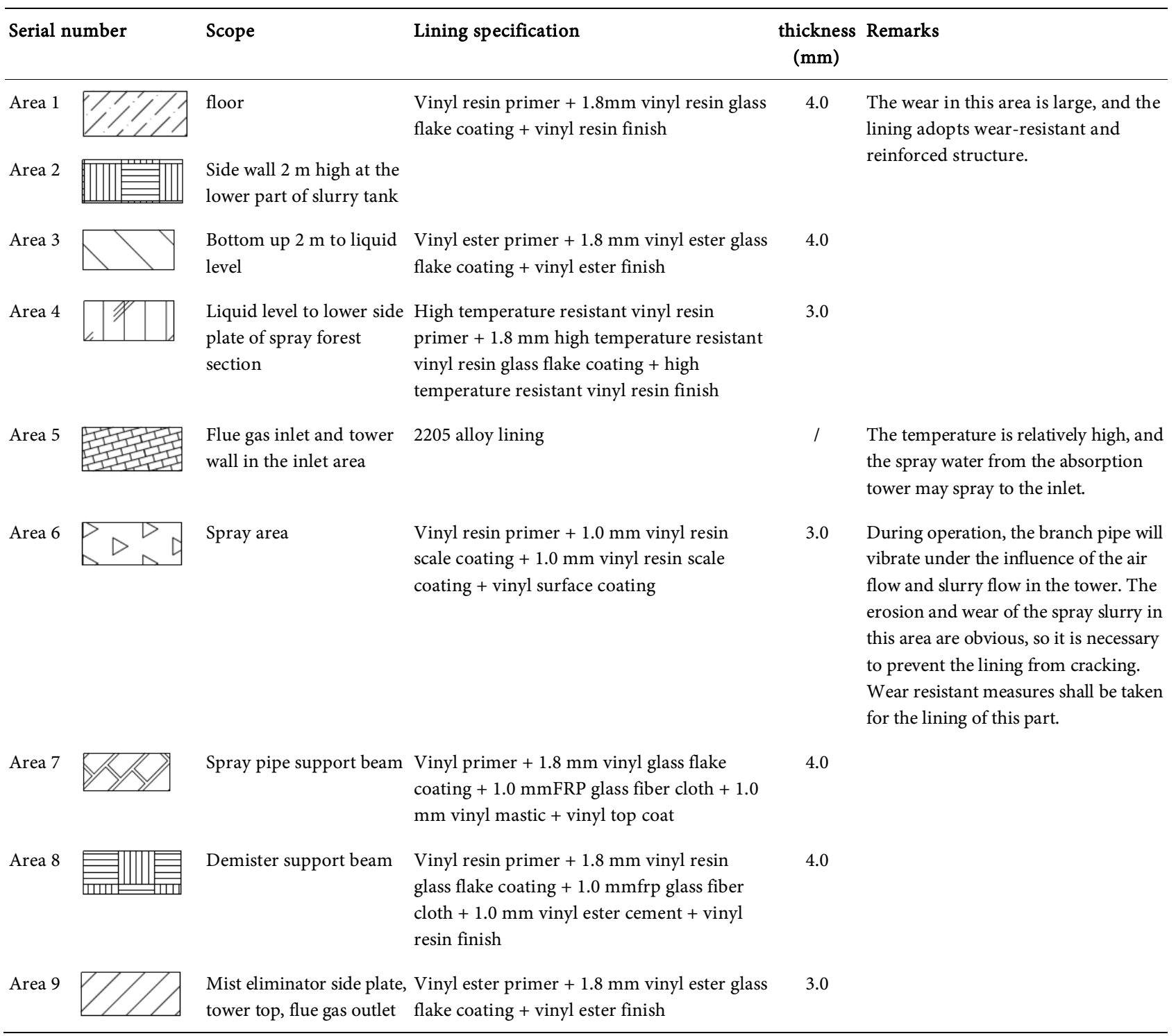

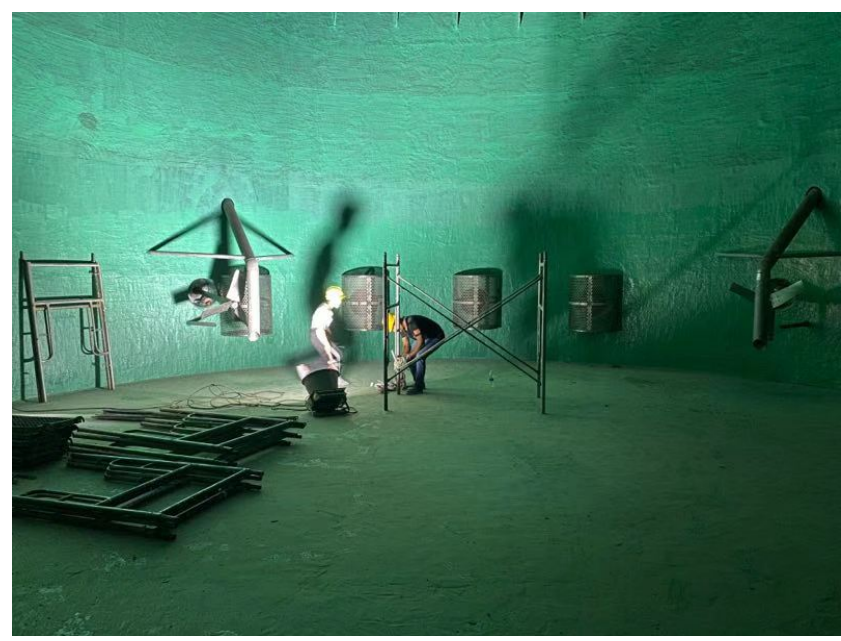

Figure 4. Bottom plate and side plate of absorption tower coated with nonmetallic glass scales. 


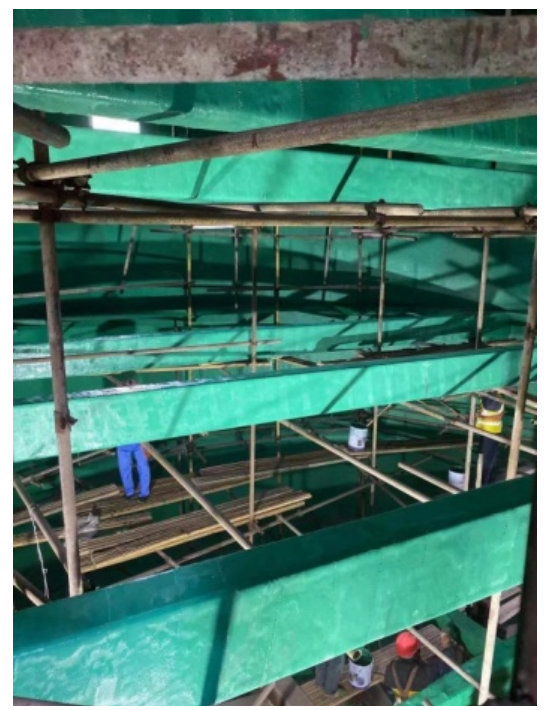

Figure 5. Desulfurization spray layer coated with glass scales.

Table 2. Requirements for selection of anticorrosive materials for steel inner barrel of sleeve or multi tube chimney.

\begin{tabular}{|c|c|c|c|c|c|c|c|}
\hline & & & \multicolumn{5}{|c|}{ Flue gas type } \\
\hline & \multirow{2}{*}{\multicolumn{2}{|c|}{ Chimney type }} & \multicolumn{3}{|c|}{ Dry flue gas } & \multirow{2}{*}{$\begin{array}{l}\text { Damp } \\
\text { flue gas }\end{array}$} & \multirow{2}{*}{$\begin{array}{l}\text { Wet } \\
\text { flue gas }\end{array}$} \\
\hline & & & $\begin{array}{c}\text { Weak } \\
\text { corrosiveness }\end{array}$ & $\begin{array}{l}\text { Moderate } \\
\text { corrosion }\end{array}$ & $\begin{array}{l}\text { Strong } \\
\text { corrosion }\end{array}$ & & \\
\hline \multirow[t]{8}{*}{ Sleeve or multi pipe chimney } & \multicolumn{2}{|l|}{ Brick chimney } & O & $\square$ & $x$ & $x$ & $\times$ \\
\hline & \multicolumn{2}{|c|}{ Single barrel reinforced concrete chimney } & O & $\square$ & $\triangle$ & $\triangle$ & $\times$ \\
\hline & \multicolumn{2}{|c|}{ Brick inner tube } & $\square$ & O & ○ & $\square$ & $\times$ \\
\hline & \multirow[t]{5}{*}{ Steel chimney } & Anticorrosive metal lining & $\triangle$ & $\triangle$ & $\square$ & $\square$ & O \\
\hline & & Anticorrosive light brick lining & $\triangle$ & $\triangle$ & $\square$ & $\square$ & O \\
\hline & & Anticorrosive coating lining & $\square$ & $\square$ & $\square$ & $\square$ & $\square$ \\
\hline & & Acid resistant concrete lining & $\square$ & $\square$ & $\square$ & $\triangle$ & $x$ \\
\hline & & FRP inner cylinder & $\triangle$ & $\triangle$ & $\square$ & $\square$ & O \\
\hline
\end{tabular}

Note: "O" suggested scheme; “ $\square$ " available scheme; " $\triangle$ " unsuitable scheme; “ $x$ " not applicable scheme.

pipe, the selection requirements of corrosion protection measures with high reliability shall be adopted". As there is no industry standard for wet desulfurization of cement kiln, it should be selected according to the fire industry.

At present, there are many anti-corrosion technologies for chimney after wet desulfurization in China, including FRP, titanium alloy composite steel plate, anti-corrosion coating, foam glass brick and vitrified ceramic brick.

The advantages of using FRP as anticorrosive material for the inner wall of chimney are: good integrity, simple installation, light weight, convenient processing, strong anticorrosive ability and low cost. However, as anticorrosive system of chimney, the temperature of flue gas should be strictly controlled. As FRP is a polymer plastic matrix composite.

Therefore, its high-temperature resistance is poor. When the temperature of 
the flue gas in contact with it increases, the structural performance of FRP will decline sharply in a long time.

Due to the low cost of coating anticorrosion, but the construction quality is difficult to guarantee, the poor durability is easy to cause the fall off of anticorrosive coating. The anti-corrosion cost of titanium plate steel inner cylinder is the highest, and the load is increased greatly. If the reconstruction is carried out on the basis of the original chimney, the construction is too difficult, and the general factory cannot bear the high reconstruction cost and long construction period. The foamed glass brick and vitrified ceramic brick can be directly adhered to the inner wall of the original chimney to form a good anticorrosive coating and the construction period is short. The abrasion resistance of the foamed glass brick is worse than that of vitrified ceramic brick. It is easy to cause the brick to become thinner after a long time of Scouring at the part with high velocity of the chimney, and the later repair is more difficult. The properties of vitrified ceramic brick are better.

In a $5000 \mathrm{t} / \mathrm{d}$ cement production line constructed by Hefei Institute, the original chimney is concrete chimney, which has been in operation for many years, and there is corrosion. In the reconstruction of wet desulfurization project, in order to solve the corrosion problems of the original chimney and wet desulfurization chimney at the same time, vitrified ceramic brick + temperature resistant and acid resistant adhesive process is adopted. See Figure 6 for the constructed chimney. The project has been running for one year, and the inner wall of the chimney is corroded well.

\subsection{Selection of Anticorrosive Materials for Slurry Pipeline}

Wear is the first consideration in the selection of slurry pipeline, because it has an impact on the service life and performance of the pipeline. The properties of desulfurization slurry require that the pipeline must have good corrosion and wear resistance. From the perspective of wear resistance, the greater the hardness or elasticity is, the stronger the wear resistance is. Therefore, rubber lining

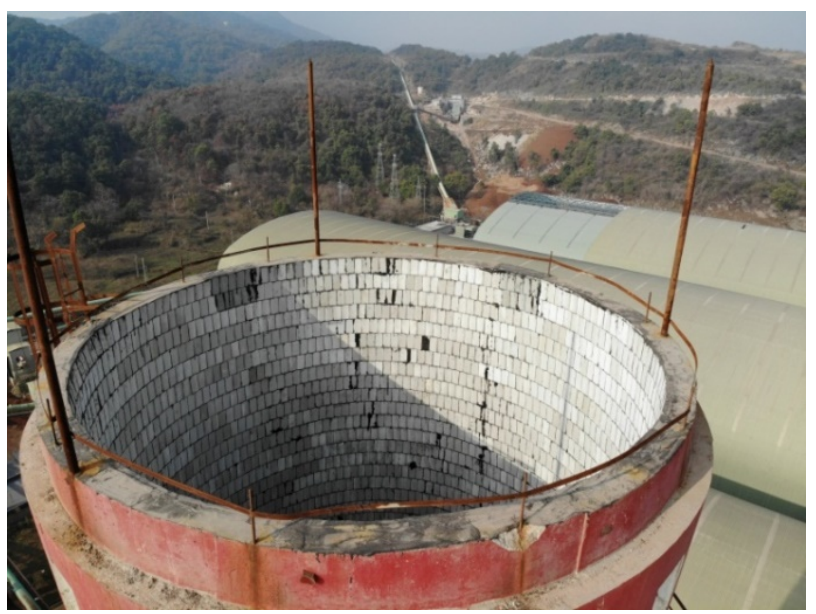

Figure 6. Wet desulfurization chimney with vitrified ceramic brick anticorrosion. 
and all metal structure are adopted. Such as carbon steel rubber lining, austenitic stainless steel material, etc.

As shown in Figures 7-8, it is the actual pipeline application of FGD project of Hefei Institute. For pipes with carbon steel and rubber lining, the rubber lining will fall off due to the wear of particles. Cause system blockage. Because the small pipe adopts carbon steel rubber lining, the pipe diameter will be reduced due to the thickness of the rubber lining, so the pipe diameter should be enlarged during the design. It is suggested that in the design of desulfurization system pipes, small diameter pipes $(\mathrm{DN} \leq 150)$ can be made of stainless steel for maintenance and replacement, large diameter pipes $(\mathrm{DN} \geq 150)$ can be made of fiberglass or carbon steel with rubber lining.
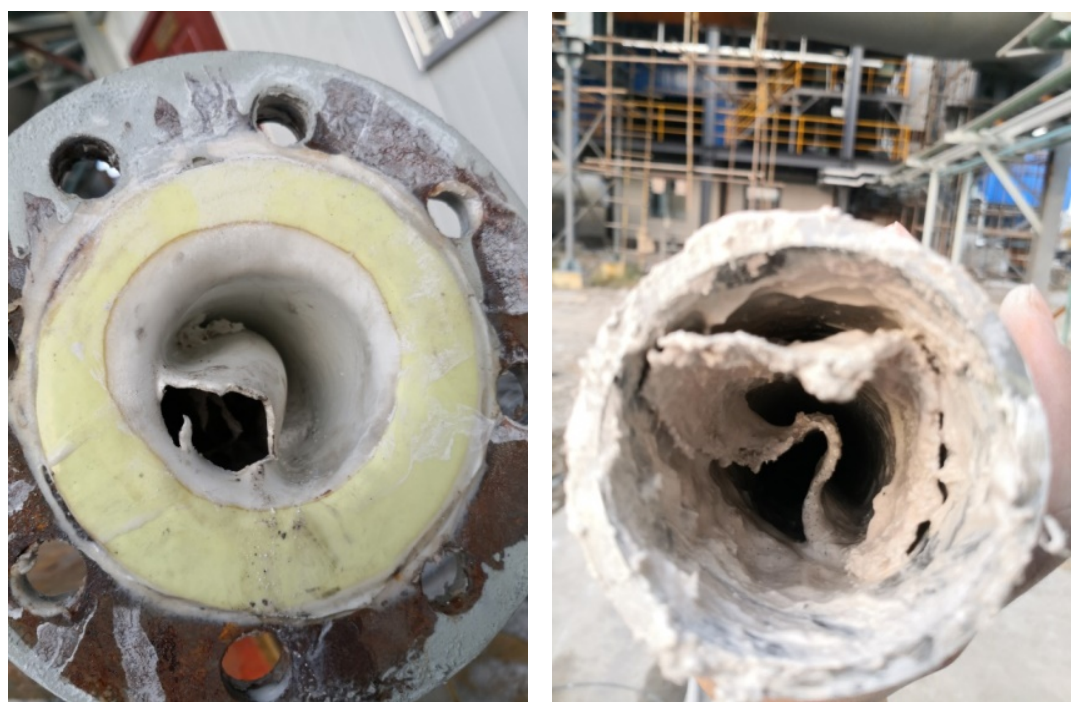

Figure 7. Falling off of rubber lining of wet desulfurization carbon steel + rubber lined pipeline

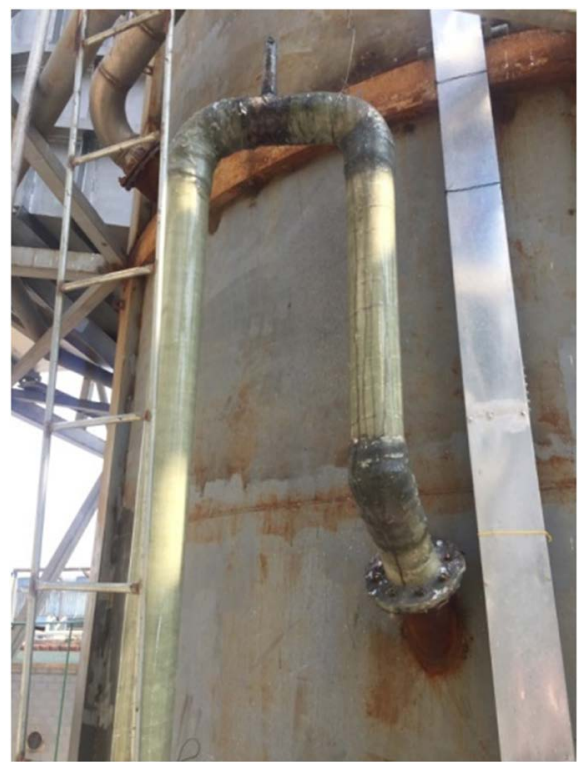

Figure 8. Glass fiber reinforced plastic pipeline for wet desulfurization. 


\section{Conclusions}

This paper discusses the corrosion environment of wet desulfuration absorption tower, chimney, slurry pipeline, etc. in the operation of cement kiln, and puts forward the selection of anticorrosive materials and operation experience combined with practical engineering cases, and puts forward anticorrosive suggestions:

1) It is suggested to use alloy materials, such as 2205 alloy, to prevent the corrosion of the flue in the front $2 \mathrm{~m}$ of the desulfurization tower;

2) In terms of economy and service life, it is recommended to adopt glass flake lining for anticorrosion of desulfurization tower body. Due to different corrosion environment in different parts, the lining thickness is different;

3) For anticorrosion of desulfurization system pipeline, stainless steel, carbon steel rubber lining or glass fiber reinforced plastic material shall be selected according to the actual situation and considering the economy;

4) The actual case shows that vitrified ceramic brick is a better way to prevent corrosion of chimney after desulfurization.

\section{Conflicts of Interest}

The author declares no conflicts of interest regarding the publication of this paper.

\section{References}

[1] Li, B.S., Zhao, L.L., et al. (2009) Corrosion and Protection of Wet Flue Gas Desulfurization Unit. Chemical Engineering \& Machinery, 6, 640-641.

[2] Yuan, Y.Q. and Liao, Y.J. (2010) Corrosion Environment at Abaorber Inlet of Wet Desulfurization System and Anti-Corrosion Program. Guangdong Electric Power, NO. 5, 20-22.

[3] Yin, X.H., Zhang, J.L., Tong, Y., Zhang, L. and Bi, H.Y. (2012) Corrosion Analysis and Anti-Corrosion Measure of Desulphurization System for Coal-Fired Power Plant. Heilongjiang Electric Power, 34, 128-129.

[4] Han, W. (2009) GGH WFGD Device Settings of Techno-Economic Aanlysisi and Environmental Impact. Energy Environmental Protection, 5, 5-8.

[5] Wei, D.X., Song, G.C. and Xue, Y.J. (2019) Discussion on Anticorrosion of Hot Desulfurization Chimney of Heating Boiler. Chemical Engineering Design Communications, No. 1.

[6] Mao, J.X., Pan, L. and Li, W.H. (2016) Discussion on the Present Situation of Anticorrosion of Wet Desulfurization Chimney. Journal of Green Science and Technology, 22, 93-95. 